EXTENDED REPORT

\title{
Cardiovascular admissions and mortality in an inception cohort of patients with rheumatoid arthritis with onset in the 1980s and 1990s
}

\author{
N Goodson, J Marks, M Lunt, D Symmons
}

See end of article for authors' affiliations

Correspondence to: Professor Deborah

P M Symmons, ARC

Epidemiology Unit, Stopford Building, University of Manchester, Oxford Road, Manchester M13 9PT; deborah. symmons@man.ac.uk

Accepted 6 April 2005 Published Online First 20 April 2005

Background: There is increased cardiovascular disease mortality in rheumatoid arthritis. This may reflect an increased prevalence of cardiovascular disease or an increased case fatality in patients with rheumatoid arthritis.

Objectives: To examine whether rheumatoid patients with disease onset in the 1980s-1990s have increased mortality, and to compare cardiovascular admission rates in rheumatoid patients with those of the general population.

Methods: An inception cohort of 1010 rheumatoid patients attending Stockport rheumatology clinics between 1981 and 1996 was followed up to December 2002 through the Office for National Statistics. Standardised mortality ratios (SMR) were calculated for all-cause and cause specific mortality, using the population of Stockport as reference. Cardiovascular disease admission rates were ascertained for a subgroup of patients using national hospital episode statistics; standardised cardiovascular disease admission rates (SAR) and SMRs were calculated for this subgroup.

Results: 470 patients (48\%) died during a median follow up of 11.4 years. All-cause mortality was increased in men (SMR = 1.45 (95\% confidence interval, 1.22 to 1.71$)$ ) and women (SMR=1.84 (1.64 to 2.05)), as was cardiovascular disease mortality in men (SMR $=1.36$ (1.04 to 1.75) and women (SMR $=1.93$ (1.65 to 2.26)). No difference in cardiovascular disease admission rates was observed in men (SAR 1.20 (0.89 to 1.58) or women (SAR $=1.10(0.88$ to 1.36)), despite excess cardiovascular disease mortality in this subgroup.

Conclusions: Patients with rheumatoid arthritis have reduced life expectancy and excess cardiovascular disease mortality. Nevertheless, standardised admission rates for cardiovascular disease were not raised. This suggests either that cardiovascular disease in rheumatoid arthritis has a higher case fatality than in the general population or that it offen goes unrecognised before the fatal event.

M ost mortality studies in patients with rheumatoid arthritis published since 1950 have shown an increased mortality from cardiovascular disease. ${ }^{1}$ There is now intense interest in verifying and quantifying this excess cardiovascular disease risk and understanding the underlying mechanisms.

Most previous mortality studies examined cohorts of patients with established rheumatoid arthritis. ${ }^{2-4}$ This may cause selection bias towards more severe progressive disease and left censorship. The study of inception cohorts of rheumatoid patients is less likely to reveal decreased survival rates because of the potential to include patients with milder disease. ${ }^{5}$ Several recently reported mortality studies ${ }^{6-11}$ have followed patients from early in their rheumatoid disease process. Four of these studies ${ }^{7-9}$ failed to identify any increased mortality in rheumatoid patients with disease onset during the 1980s to 1990s. One study showed that mortality from acute myocardial infarction declined in patients with onset of rheumatoid disease in more recent decades. ${ }^{11}$ Possible explanations for the relative improvement in survival of patients with rheumatoid arthritis include the earlier introduction of disease modifying treatments ${ }^{8} 9$ or a change in the natural history of rheumatoid arthritis, ${ }^{7}$ with the disease becoming less severe over recent years. ${ }^{12}$ It is possible that excess mortality in these rheumatoid cohorts could be identified with continued long term follow up. ${ }^{13}$

However, excess mortality from cardiovascular disease was observed in a primary care based cohort of patients with early seropositive inflammatory arthritis. ${ }^{10}$ Data from the Mayo clinic also suggest that the excess mortality associated with rheumatoid arthritis did not fall during the 1980s to 1990s. ${ }^{14}$ A study of rheumatoid patients identified from the Swedish hospital discharge register reported that, although mortality rates fell towards the end of the last century, mortality from coronary heart disease remained particularly high in rheumatoid arthritis. ${ }^{15}$ Thus it is difficult to know whether the survival prospects of rheumatoid patients have changed in recent years. Long term follow up of rheumatoid arthritis inception cohorts is required.

One possible explanation for the excess cardiovascular disease mortality in rheumatoid arthritis is an increased prevalence of comorbid cardiovascular disease. Studies in the USA have shown that rheumatoid patients have higher rates of cardiovascular disease events than in the general population $^{16}{ }^{17}$ and describe cardiovascular disease comorbidity more often in rheumatoid arthritis than in osteoarthritis. ${ }^{18}$ However, there have also been reports that rheumatoid patients are more likely to experience silent ischaemic heart disease and sudden cardiac death than the general population. ${ }^{19}$ An alternative explanation for the increased cardiovascular disease mortality in rheumatoid arthritis could be that these patients have an increased case fatality rate from cardiovascular disease events.

Our aims in this study were therefore, first, to examine whether rheumatoid patients with disease onset in the 1980s to 1990s, identified in a hospital clinic setting, have increased

Abbreviations: HES, hospital episode statistics; IQR, interquartile range; ONS, Office for National Statistics; RF, rheumatoid factor; SAR, standardised admission rate; SMR, standardised mortality ratio 
Table 1 Descriptive data and mortality data for the rheumatoid arthritis cohort

\begin{tabular}{|c|c|c|c|}
\hline Descriptive data & Women $(n=729)$ & Men $(n=281)$ & Total $(n=1010)$ \\
\hline $\begin{array}{l}\text { †Age at presentation (years) } \\
\text { †Age (RF-) (years) } \\
\text { †Age (RF+) (years) } \\
\text { RF+ at time of diagnosis } \\
\text { RF- at time of diagnosis } \\
\text { †Cause of death } \\
\text { Cardiovascular } \\
\text { Respiratory } \\
\text { Neoplastic } \\
\text { Other mortality } \\
\text { Total mortality }\end{array}$ & $\begin{array}{l}60.4(49.8 \text { to } 69.9) \\
62.5(49.9 \text { to } 71.9) \\
59.8(49.8 \text { to } 69.3) \\
542(74.3 \%) \\
187(25.7 \%) \\
\text { Women }(n=711) \\
158(22.2 \%) \\
51(7.2 \%) \\
52(7.3 \%) \\
67(9.4 \%) \\
328(46.1 \%)\end{array}$ & $\begin{array}{l}60.3(51.7 \text { to } 68.3) \\
63.8(55.1 \text { to } 72.9) \\
59.6(50.3 \text { to } 67.0) \\
229(81.8 \%) \\
52(18.2 \%) \\
\text { Men }(\mathbf{n}=268) \\
62(23.1 \%) \\
26(9.7 \%) \\
36(13.4 \%) \\
18(6.7 \%) \\
142(53.0 \%)\end{array}$ & $\begin{array}{l}60.4(50.4 \text { to } 69.6) \\
63.1(51.6 \text { to } 72.5) \\
59.7(49.9 \text { to } 68.8) \\
772(76.4 \%) \\
238(23.6 \%) \\
\text { Total }(n=979) \\
220(22.5 \%) \\
77(7.9 \%) \\
88(9.0 \%) \\
85(8.7 \%) \\
470(48.0 \%)\end{array}$ \\
\hline \multicolumn{4}{|c|}{$\begin{array}{l}\text { Values are median (interquartile range) or } \mathrm{n}(\%) \text {. } \\
\text { †Date of birth not known for two patients in the cohort. } \\
\text { †Mortality data not available for } 31 \text { patients. } \\
\text { RF-/RF+, rheumatoid factor negative/positive. }\end{array}$} \\
\hline
\end{tabular}

mortality compared with the local general population; and second, to compare cardiovascular admission rates in rheumatoid patients with those of the general population.

\section{METHODS \\ Setting}

Stockport is a large urban area, south of Manchester, UK, with a population of nearly 285000 .

\section{Stockport rheumatoid arthritis register}

This inception cohort of 1010 patients with rheumatoid arthritis was identified from a register of all newly diagnosed cases, based on a consultant rheumatologist's opinion, who were attending Stockport rheumatology outpatient clinics between 1981 and 1996. Patients were designated as seropositive if, at the time of diagnosis, they had either an IgM rheumatoid factor (RF) titre of $1: 40$ or above, or rheumatoid nodules. Many of these patients were subsequently discharged from regular rheumatology follow up. Thus, unlike many previously described hospital based cohorts, $^{20-24}$ the Stockport rheumatoid arthritis cohort is composed of patients with a broad spectrum of rheumatoid disease severity and is not restricted to those under long term rheumatology follow up.

Approval for the study was given by the Stockport local research ethics committee.

\section{Mortality study}

Patients and methods

Identification data including NHS numbers, names, dates of birth, and last known address were sent to the Office for
National Statistics (ONS) for flagging and notification of deaths using the NHS Central Register. ${ }^{25}$ ONS were able to match 979 of the 1010 patients (97\%) and provided death drafts for all patients who died before 31 December 2002. The causes of death were coded according to World Health Organisation (WHO) rules using the International Classification of Diseases, ninth revision (ICD-9) until the 1 January 2001, when ICD-10 coding was introduced.

The Stockport district population was used as the reference group for calculating standardised mortality ratios (SMRs). ONS provided mortality rates for all causes, cardiovascular causes, respiratory causes, and neoplasia, for men and women separately in 10 year age bands, for the years 1982 to 2001. Population death rates for the year 2002 were not available at the time of analysis, and cohort mortality rates in this year were compared with those in 2001. All-cause and cause specific SMRs were calculated using indirect standardisation (STATA-7). Cox regression was used to examine whether RF status predicted mortality in the rheumatoid arthritis cohort, adjusting for age and sex. The Cox model's proportional hazards assumptions were tested graphically using the stphplot command in STATA-7.

\section{Cardiovascular admissions study}

Patients and methods

Patients in the Stockport rheumatoid arthritis cohort who were Stockport Health Authority residents between 1994 and 2002 were identified by matching NHS numbers, dates of birth, and names. Dates of entering and leaving the health authority register were recorded. Stockport Public Health Department provided hospital episode statistics (HES ${ }^{26}$ for

Table 2 Cardiovascular causes of death grouped by ICD9 /ICD 10 coding

\begin{tabular}{|c|c|c|c|c|c|}
\hline Cardiovascular main causes of death & ICD-9 codes & ICD- 10 codes & Female (n) & Male (n) & All RA (n) \\
\hline Chronic rheumatic heart disease & $393-398$ & $105-109$ & 2 & 0 & 2 \\
\hline Hypertensive disease & $401-405$ & $110-115$ & 4 & 0 & 4 \\
\hline Acute $\mathrm{MI}$ & 410 & 121,122 & 46 & 26 & 72 \\
\hline Acute/subacute IHD & 411 & 124 & 1 & 0 & 1 \\
\hline Chronic IHD & 414 & 125 & 36 & 16 & 52 \\
\hline Ischaemic heart disease (total) & $410-414$ & $120-125$ & 83 & 62 & 125 \\
\hline Pulmonary circulation & $415-417$ & $126-128$ & 6 & 3 & 9 \\
\hline Other forms of heart disease & $420-429$ & $130-152$ & 17 & 5 & 22 \\
\hline Cerebrovascular disease. & $430-438$ & $160-169$ & 40 & 8 & 48 \\
\hline Disease of arteries, arterioles, and capillaries & $440-448$ & $170-179$ & 4 & 4 & 8 \\
\hline Diseases of veins and lymphatics and other diseases of the circulatory & & & 2 & 0 & 2 \\
\hline system & $451-459$ & $180-189$ & & & \\
\hline Other unspecified circulatory disorders & & $195-199$ & 0 & 0 & 0 \\
\hline Total number of cardiovascular disease deaths & $390-459$ & $100-199$ & 158 & 62 & 220 \\
\hline
\end{tabular}


Table 3 Standardised mortality ratios (SMRs) for Stockport rheumatoid arthritis cohort

\begin{tabular}{|c|c|c|c|c|c|c|c|c|}
\hline \multirow[b]{2}{*}{ Cause of death } & \multicolumn{4}{|c|}{ Women ( $n=711)$ : number of deaths } & \multicolumn{4}{|c|}{ Men $(n=268):$ number of deaths } \\
\hline & Observed & Expected & SMR & $95 \% \mathrm{Cl}$ & Observed & Expected & SMR & $95 \% \mathrm{Cl}$ \\
\hline All causes & 328 & 178.59 & 1.84 & 1.64 to 2.05 & 142 & 97.78 & 1.45 & 1.22 to 1.71 \\
\hline CVD & 158 & 81.56 & 1.93 & 1.65 to 2.26 & 62 & 45.48 & 1.36 & 1.04 to 1.75 \\
\hline IHD & 83 & 42.52 & 1.95 & 1.55 to 2.41 & 42 & 28.67 & 1.46 & 1.05 to 1.98 \\
\hline MI & 47 & 26.00 & 1.77 & 1.30 to 2.36 & 26 & 18.89 & 1.38 & 0.90 to 2.02 \\
\hline Respiratory & 51 & 23.45 & 2.18 & 1.61 to 2.86 & 26 & 14.52 & 1.79 & 1.17 to 2.62 \\
\hline Neoplasms & 52 & 46.93 & 1.11 & 0.82 to 1.45 & 36 & 26.76 & 1.35 & 0.94 to 1.86 \\
\hline
\end{tabular}

all NHS hospital admission episodes, coded with primary diagnoses of cardiovascular disease, (ICD-9 codes 390-459 and ICD-10 codes I00-I99), ischaemic heart disease (ICD-9 codes 410-414 and ICD-10 codes I20-I25), and myocardial infarction (ICD-9 codes 410, 412 and ICD-10 codes I21-I22), for Stockport Health Authority residents between years 1994 and 2002. Population rates of admissions for cardiovascular disease, ischaemic heart disease, and myocardial infarction were calculated for each year using the Stockport Health Authority population estimates as the denominator (taken in October 1999 as the mid-point of the study period).

In all, 515 of the Stockport rheumatoid arthritis cohort were identified as being residents in Stockport Health Authority between 1994 and 2002. The incidence of cardiovascular disease, primary diagnosis, and admissions in the prevalent Stockport rheumatoid arthritis cohort were compared with the rate of admissions for cardiovascular disease as a primary diagnosis in the general Stockport population to calculate a standardised cardiovascular admission rate (SAR) for the rheumatoid cohort. SARs for the diagnoses of cardiovascular disease, ischaemic heart disease, and myocardial infarction for the years 1994 to 2002 were calculated using STATA-7. The start of follow up was 1 April 1994, or the date of entry to the health authority. The end of the follow up period was the date of death, the date of leaving the health authority, or the end of the study period (31 March 2002). Each patient admitted with cardiovascular disease was censored on the date of admission and a new period of follow up was started. Patients with multiple admissions contributed several periods of person years of follow up.

SMRs for this prevalent rheumatoid subgroup were calculated for all-cause, cardiovascular disease, ischaemic heart disease, and myocardial infarction mortality using the Stockport population mortality rates for these years.

\section{RESULTS}

\section{Mortality study}

Date of birth, sex, year of diagnosis, and rheumatoid factor status at diagnosis were recorded for 1008 of the 1010 patients. There were 729 women (72\%) and 279 men (28\%) and the median age at diagnosis was 60.4 years (interquartile range (IQR), 50.4 to 69.6) (table 1).

An attempt was made to validate the consultant diagnosis of rheumatoid arthritis. The medical records of 20 patients, selected randomly from the Stockport rheumatoid arthritis register, were reviewed, and 18 patients met American college of Rheumatology (ACR) classification criteria for rheumatoid arthritis. There was insufficient clinical information recorded to classify two patients.

The 979 patients (97\%) matched by ONS were used in the initial mortality analysis. The median follow up period was 11.4 years (IQR, 7.5 to 15.4). By 31 December 2002, 470 patients $(48 \%)$ had died. The median age at death was 74.9 years $(68.8$ to 81.0$)$. Women died at an older age ( 76.0 years
(70.2 to 81.4$)$ ) than men (72.2 years $(66.1$ to 78.9$))$, and patients who were RF negative died at an older age (79.6 years (71.7 to 84.8$)$ ) than RF positive patients ( 74.3 years (68.0 to 79.9$))$.

\section{Cause of death}

Cardiovascular disease was the most frequent cause of death (table 1), responsible for $48 \%$ of female and $44 \%$ of male deaths. Ischaemic heart disease was recorded as the main cause of death in 125 cases (26\%) and acute myocardial infarction in 72 (15\%) (table 2).

Rheumatoid arthritis was identified as the underlying cause in only 36 deaths $(7.6 \%)$ and was recorded anywhere on the death certificates of 44 patients $(9 \%)$.

\section{Standardised mortality ratios}

Both male and female rheumatoid patients had higher than expected mortality rates (table 3) Mortality from all cardiovascular disease causes in women were approximately twice that expected (SMR $=1.93 \quad$ (95\% confidence interval (CI), 1.65 to 2.26)) with a more modest increase being observed in male patients $(\mathrm{SMR}=1.36$ (1.04 to 1.75$)$. The SMRs for ischaemic heart disease were raised in both men and women, and female rheumatoid patients had a higher mortality from myocardial infarction. In female rheumatoid patients, $77(51 \%)$ of the 149 excess deaths were caused by cardiovascular disease and $40(27 \%)$ of the excess deaths were from ischaemic heart disease. Cardiovascular deaths were responsible for $38 \%$ of the 44 male excess deaths, and 13 of the male excess deaths (29\%) were from ischaemic heart disease. Mortality from respiratory causes was increased in both male and female rheumatoid patients, and 36 respiratory deaths were coded as being caused by pneumonia, seven by interstitial lung disease, one from asthma, and the remaining respiratory deaths were from chronic obstructive airways disease. The number of deaths from neoplasia was not significantly different from that seen in the general population.

Men and women with seropositive rheumatoid arthritis had increased all-cause, cardiovascular disease, ischaemic heart disease, and myocardial infarction mortality compared with the general population (table 4). Seropositive women had twice the expected cardiovascular, ischaemic heart disease, and myocardial infarction mortality. Respiratory mortality was significantly increased in seropositive patients. Female seronegative patients had a modest increase in allcause and cardiovascular disease mortality. Male seronegative patients had no increase in all-cause or cause specific mortality. However, the number of patients in this subgroup was small.

\section{Predictors of mortality}

Rheumatoid factor, univariately, did not predict all-cause mortality within the rheumatoid cohort. However, RF positive patients were younger at presentation and at death. 


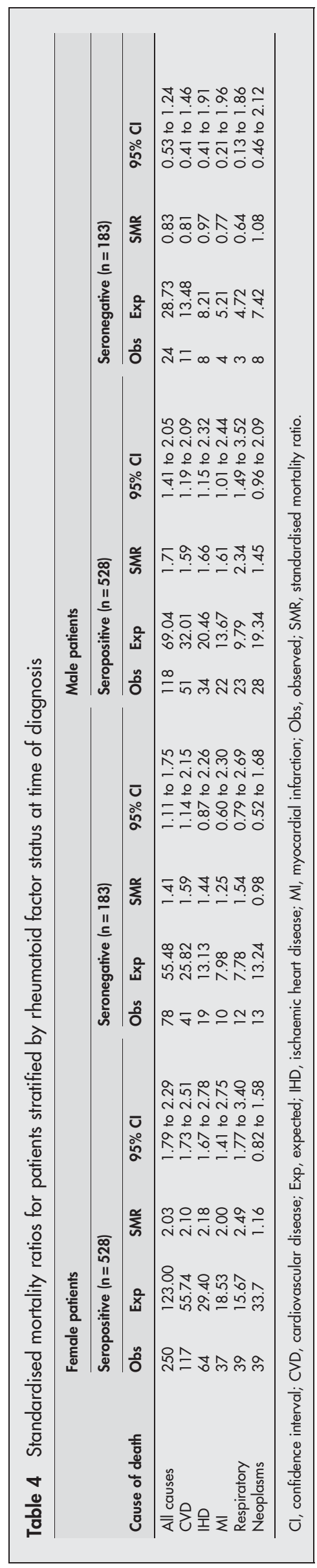

When adjusted for age at disease onset and sex, RF was a modest predictor of all-cause mortality, (hazard ratio $(\mathrm{HR})_{\mathrm{adj}}=1.55(95 \% \mathrm{CI}, 1.25$ to 1.94$\left.)\right)$, cardiovascular disease mortality $\left(\mathrm{HR}_{\mathrm{adj}}=1.37\right.$ (1.00 to 1.88$\left.)\right)$, and respiratory mortality $\left(\mathrm{HR}_{\mathrm{adj}}=1.85\right.$ (1.04 to 3.29). The proportional hazards assumption remained true for all these models.

\section{Cardiovascular admissions}

Patient characteristics

The characteristics of the 515 rheumatoid patients who were Stockport residents between 1994 and 2002 are shown in table 5 . The median disease duration was 5.8 years from the time of rheumatologist diagnosis of rheumatoid arthritis. The median age at diagnosis was 56.2 years (IQR 41.7 to 65.5 ).

The 515 patients accumulated 3173.3 person years of follow up between 1 April 1994 and 31 March 2002. During this time, $93(18 \%)$ of the rheumatoid patients experienced 134 cardiovascular disease admissions and 30\% of these patients had more than one admission. These patients were admitted to hospitals in Manchester, Stockport, and East Cheshire.

\section{Standardised admission ratios}

The SAR for cardiovascular disease was not raised in either male or female subjects (table 6). There were only small numbers of admissions with ischaemic heart disease and myocardial infarction. There were no significant increases in cardiovascular disease SARs for seropositive rheumatoid patients (female seropositive patients, SAR $=1.10(95 \% \mathrm{CI}$, 0.54 to 2.10$)$; male seropositive patients, $\mathrm{SAR}=1.44$ (0.95 to $3.32))$.

Standardised mortality ratios in the admissions cohort There were 182 deaths in this group of 515 prevalent rheumatoid patients, with 100 deaths from cardiovascular disease (table 7). Cardiovascular mortality was significantly increased in both male ( $\mathrm{SMR}=2.40(95 \% \mathrm{CI}, 1.64$ to 3.39$)$ ) and female patients ( $\mathrm{SMR}=2.77$ (2.15 to 3.51)). Women and seropositive patients had higher SMRs. Mortality from ischaemic heart disease was also increased in both sexes, but the increase was more marked in women and seropositive patients. Mortality from myocardial infarction was significantly increased in women. Approximately 15\% of all deaths in this cohort were attributed to acute myocardial infarction. There were more excess deaths from cardiovascular disease than there were excess cardiovascular disease admissions. Only 42 of the 100 patients in the rheumatoid cohort who died from cardiovascular disease had any previous cardiovascular disease admissions during the follow up period.

The median time between the first cardiovascular disease event and death was 4.8 months (IQR, 0.6 to 21.6). Cox regression adjusted for age and sex showed that a cardiovascular admission was a very strong predictor of subsequent all-cause mortality $\left(\mathrm{HR}_{\mathrm{adj}}=4.2(95 \% \mathrm{CI}, 2.9\right.$ to 5.9$\left.)\right)$ and cardiovascular disease mortality $\left(\mathrm{HR}_{\mathrm{adj}}=8.8\right.$ (5.7 to 13.6)).

\section{DISCUSSION}

These studies have shown that all-cause and cardiovascular mortality is still increased in rheumatoid patients in the United Kingdom with disease onset in the 1980s and 1990s. Mortality was higher in, but not confined to, those patients who were RF positive at baseline. It seems likely that the absence of excess mortality described in other recent studies of patients with early rheumatoid arthritis may be attributed to aggressive disease control in these patients. ${ }^{7-9}$ They were conducted in the context of early arthritis clinics where patients might experience early treatment with disease modifying antirheumatic drugs. By contrast the 
Table 5 Demographics of the 515 patients with rheumatoid arthritis monitored for cardiovascular disease admissions

\begin{tabular}{|c|c|c|c|}
\hline & $\begin{array}{l}\text { All RA patients } \\
(n=515)\end{array}$ & $\begin{array}{l}\text { Female RA patients } \\
(n=371)\end{array}$ & $\begin{array}{l}\text { Male RA patients } \\
(n=144)\end{array}$ \\
\hline $\begin{array}{l}\text { RF+ at RA diagnosis (n (\%)) } \\
\text { Age (years) start of admissions study } \\
\text { (median (IQR)) } \\
\text { Duration of RA (years) (median (IQR)) }\end{array}$ & $\begin{array}{l}388(75.3) \\
62.9(53.8 \text { to } 72.3) \\
5.8(2.8 \text { to } 9.8)\end{array}$ & $\begin{array}{l}275(74.1) \\
63.6(53.5 \text { to } 72.9) \\
5.8(2.8 \text { to } 9.8)\end{array}$ & $\begin{array}{l}113(78.5) \\
61.8(54.7 \text { to } 72.9) \\
5.8(1.8 \text { to } 8.8)\end{array}$ \\
\hline
\end{tabular}

Table 6 Standardised admission rates (SAR) for cardiovascular disease

\begin{tabular}{|c|c|c|c|c|c|c|c|c|}
\hline \multirow[b]{2}{*}{ Cause of admission } & \multicolumn{4}{|c|}{ Women ( $n=371)$ : number of admissions } & \multicolumn{4}{|c|}{ Men $(n=144)$ : number of admissions } \\
\hline & Obs & Exp & SAR & $95 \% \mathrm{Cl}$ & Obs & Exp & SAR & $95 \% \mathrm{Cl}$ \\
\hline CVD & 83 & 75.45 & 1.10 & 0.88 to 1.36 & 51 & 42.51 & 1.20 & 0.89 to 1.58 \\
\hline IHD & 18 & 21.66 & 0.83 & 0.49 to 1.31 & 10 & 16.84 & 0.59 & 0.28 to 1.09 \\
\hline MI & 10 & 7.55 & 1.34 & 0.64 to 2.46 & 4 & 5.48 & 0.73 & 0.20 to 1.87 \\
\hline
\end{tabular}

Table 7 Standardised mortality ratios for all cause and cardiovascular disease causes of mortality in the rheumatoid arthritis admissions group

\begin{tabular}{|c|c|c|c|c|c|c|c|c|c|}
\hline \multirow[b]{2}{*}{ Cause of death } & \multirow[b]{2}{*}{ RA group } & \multicolumn{4}{|c|}{ Women $(n=371)$ : number of deaths } & \multicolumn{4}{|c|}{ Men ( $n=144)$ : number of deaths } \\
\hline & & Obs & Exp & SMR & $95 \% \mathrm{Cl}$ & Obs & Exp & SMR & $95 \% \mathrm{Cl}$ \\
\hline \multirow{3}{*}{ All-cause } & All RA & 129 & 56.45 & 2.29 & 1.90 to 2.71 & 53 & 29.55 & 1.79 & 1.34 to 2.34 \\
\hline & $\mathrm{RF}+$ & 93 & 38.37 & 2.42 & 1.96 to 2.97 & 40 & 19.30 & 2.07 & 1.48 to 2.82 \\
\hline & RF- & 36 & 18.1 & 1.99 & 1.39 to 2.75 & 13 & 10.25 & 1.27 & 0.67 to 2.17 \\
\hline \multirow[t]{3}{*}{ CVD } & All RA & 68 & 24.50 & 2.77 & 2.15 to 3.51 & 32 & 13.3 & 2.40 & 1.64 to 3.39 \\
\hline & $\mathrm{RF}+$ & 50 & 16.45 & 3.04 & 2.26 to 4.00 & 24 & 8.58 & 2.79 & 1.79 to 4.16 \\
\hline & RF- & 18 & 8.06 & 2.23 & 1.32 to 3.53 & 8 & 4.72 & 1.69 & 0.72 to 3.34 \\
\hline \multirow[t]{3}{*}{ IHD } & All RA & 36 & 12.48 & 2.89 & 2.02 to 3.99 & 19 & 8.25 & 2.30 & 1.38 to 3.60 \\
\hline & $\mathrm{RF}+$ & 27 & 8.46 & 3.19 & 2.10 to 4.65 & 13 & 5.42 & 2.40 & 1.27 to 4.10 \\
\hline & RF- & 9 & 4.02 & 2.24 & 1.02 to 4.25 & 6 & 2.82 & 2.12 & 0.77 to 4.62 \\
\hline \multirow[t]{3}{*}{ MI } & All RA & 19 & 7.00 & 2.71 & 1.63 to 4.24 & 8 & 4.92 & 1.62 & 0.70 to 3.20 \\
\hline & $\mathrm{RF}+$ & 15 & 4.75 & 3.15 & 1.76 to 5.20 & 6 & 3.26 & 1.83 & 0.67 to 4.00 \\
\hline & RF- & 4 & 2.24 & 1.78 & 0.48 to 4.56 & 2 & 1.65 & 1.20 & 0.13 to 4.36 \\
\hline
\end{tabular}

$\mathrm{Cl}$, confidence interval; CVD, cardiovascular disease; Exp, expected; IHD, ischaemic heart disease; MI, myocardial infarction; Obs, observed; RA, rheumatoid arthritis; RF+/-, rheumatoid factor positive/negative; SMR, standardised mortality ratio.

Stockport rheumatoid arthritis cohort was managed in routine rheumatology outpatient departments and many patients were followed up in primary care.

Other studies have also observed a greater excess mortality in female than male rheumatoid patients. ${ }^{27}{ }^{28}$ This sex difference may be deceptive, in that population rates of cardiovascular disease are lower in women than in men. Thus if rheumatoid arthritis had the same impact in men and women with respect to cardiovascular disease, one would expect higher SMRs for women given the smaller number of expected cases in the denominator.

In the current rheumatoid arthritis cohort, cardiovascular disease admission rates were not increased, despite the fact that cardiovascular disease mortality was twice that observed in the general population. One possible explanation could be that rheumatoid patients are less likely to experience multiple cardiovascular disease admissions than the general population. Of the rheumatoid patients admitted to hospital, $70 \%$ had only one cardiovascular disease admission during the eight years of follow up. This situation might occur if rheumatoid patients were more likely to die after or during their first cardiovascular disease admission. If rheumatoid patients are less likely to experience or interpret significant angina symptoms they would be less likely to present at secondary care for treatment. This may lead to increased rates of unrecognised myocardial infarction and sudden cardiac death. ${ }^{19}$ During the period of this study $34(52 \%)$ of the rheumatoid patients identified as having cardiovascular disease admissions died after their first such admission. Unfortunately, the number of first cardiovascular disease admissions for the general population was not available. Thus it was not possible to compare the number of first cardiovascular disease events in the rheumatoid cohort and the general population.

The study of respiratory outcomes was not one of the main aims of this study. However, we observed increased respiratory mortality in the rheumatoid patients, and seropositive disease was a predictor of respiratory death after adjusting for age and sex. Possible explanations for the increased respiratory mortality include respiratory complications of rheumatoid arthritis, although only a few deaths were caused by interstitial lung disease, or the effects of cigarette smoking, which is identified as a risk factor for rheumatoid arthritis and seropositive disease. ${ }^{29}$ We were not able to examine associations between smoking and mortality in this study. 
A strength of this study is that it was able to identify hospital admissions throughout the country for both the rheumatoid arthritis cohort and the local population controls.

The study has some limitations. Inclusion on the rheumatoid arthritis register was based on consultant diagnosis rather than application of the 1987 ACR classification criteria for rheumatoid arthritis. ${ }^{30}$ While this method lends a degree of external validity - as a consultant rheumatologist made the clinical diagnosis of rheumatoid arthritis, which reflects common rheumatological practice-it may have introduced misclassification bias. It is likely that simply using a consultant diagnosis of rheumatoid arthritis will have included patients with inflammatory polyarthritis who did not meet four of the seven ACR classification criteria. These patients might be expected to have milder disease and therefore make it more difficult to detect an association with increased cardiovascular disease mortality.

Baseline data on disease severity and disability were not collected, nor was information on smoking, social history, or comorbid conditions recorded. Opportunities to look for predictors of mortality within the cohort were therefore limited.

This study relies on death certificate data for the main cause of death and hospital episode statistics for the main cause of admission. There are several limitations that can give rise to inaccuracies in mortality ${ }^{31} 32$ and admission data, ${ }^{33} 34$ although it seems that the accuracy of coding for specific admission diagnoses has improved over recent years. ${ }^{35}$ However, as population mortality and admission data are subject to the same inaccuracies it is unlikely that this will have introduced significant bias. Conversely if cardiovascular disease is more likely to remain clinically silent in rheumatoid arthritis, it is probable that cardiovascular disease diagnoses will be recorded less often as the primary cause of admission in this group. This may explain the similar rates of cardiovascular disease admissions observed in this study. As described by others, rheumatoid arthritis was recorded infrequently on the death certificates of these patients. ${ }^{36} 37$

In summary, patients who have developed rheumatoid arthritis in the last two decades continue to experience excess cardiovascular mortality in the 21 st century. This excess mortality is not reflected by an increase in cardiovascular disease admissions. This may reflect a high mortality during the first event or a failure to diagnose cardiovascular disease before death.

\section{ACKNOWLEDGEMENTS}

NG was supported by a clinical fellowship awarded by the Devonshire Royal Hospital Trust, Buxton. The work of the ARC Epidemiology Unit is funded by a programme grant from the Arthritis Research Campaign, UK.

We are grateful for the help of the Stockport Primary Care Trust and Public Health Informatics Departments at Stepping Hill Hospital and Dr Kate Morgan, Consultant Histopathologist at Stepping Hill Hospital.

\section{Authors' affiliations}

N Goodson, M Lunt, D Symmons, ARC Epidemiology Unit, Stopford Building, University of Manchester, Manchester, UK

J Marks, Department of Rheumatology, Stepping Hill Hospital, Stockport, UK

\section{REFERENCES}

1 Boers M, Dijkmans B, Gabriel S, Maradit-Kremers H, O'Dell J, Pincus T. Making an impact on mortality in rheumatoid arthritis: targeting cardiovascular comorbidity. Arthritis Rheum 2004;50:1734-9.

2 Wolfe F, Mitchell DM, Sibley JT, Fries JF. The mortality of rheumatoid arthritis. Arthritis Rheum 1994;37:481-94.

3 Wallberg-Jonsson S, Ohman ML, Rantapaa-Dahlqvist S. Cardiovascular morbidity and mortality in patients with seropositive rheumatoid arthritis in northern Sweden. J Rheumatol 1997;24:445-51.
4 Watson DJ, Rhodes T, Guess HA. All-cause mortality and vascular events among patients with rheumatoid arthritis, osteoarthritis, or no arthritis in the UK General Practice Research Database. J Rheumatol 2003;30:1 196-202.

5 Ward MM. Recent improvements in survival in patients with rheumatoid arthritis: better outcomes or different study designs? Arthritis Rheum 2001;44:1467-9

6 Sokka T, Mottonen T, Hannonen P. Mortality in early "sawtooth" treated rheumatoid arthritis patients during the first 8-14 years. Scand J Rheumatol 1999;28:282-7.

7 Lindqvist E, Eberhardt K. Mortality in rheumatoid arthritis patients with disease onset in the 1980s. Ann Rheum Dis 1999;58:11-14.

8 Kroot EJ, van Leeuwen MA, van Rijswijk MH, Prevoo ML, Van't Hof MA, van de Putte $L B$, et al. No increased mortality in patients with rheumatoid arthritis: up to 10 years of follow up from disease onset. Ann Rheum Dis 2000;59:954-8.

9 Peltomaa R, Paimela L, Kautiainen H, Leirisalo-Repo M. Mortality in patients with rheumatoid arthritis treated actively from the time of diagnosis. Ann Rheum Dis 2002;61:889-94.

10 Goodson NJ, Wiles NJ, Lunt M, Barrett E, Silman AJ, Symmons DP. Mortality in Early Inflammatory Polyarthritis: Cardiovascular Mortality Is Increased in Seropositive Patients. Arthritis Rheum 2002;46:2010-19.

11 Krishnan E, Lingala VB, Singh G. Declines in mortality from acute myocardial infarction in successive incidence and birth cohorts of patients with rheumatoid arthritis. Circulation 2004;110:1774-9.

12 Silman AJ. Has the incidence of rheumatoid arthritis declined in the United Kingdom? Br J Rheumatol 1988;27:77-9.

13 Lindqvist E, Geborek P, Saxne T, Eberhardt K. Mortality in Rheumatoid Arthritis Patients with Disease Onset in the 1980s. Arthritis Rheum 2004;50(9 supp):959s.

14 Gabriel SE, Crowson CS, O'Fallon WM. Mortality in rheumatoid arthritis: have we made an impact in 4 decades? J Rheumatol 1999;26:2529-33.

15 Bjornadal L, Baecklund E, Yin L, Granath F, Klareskog L, Ekbom A. Decreasing mortality in patients with rheumatoid arthritis: Results from a large population based cohort in Sweden, 1964-95. J Rheumatol 2002;29:906-12.

16 del Rincon ID, Williams K, Stern MP, Freeman GL, Escalante A. High incidence of cardiovascular events in a rheumatoid arthritis cohort not explained by traditional cardiac risk factors. Arthritis Rheum 2001;44:2737-45

17 Solomon DH, Karlson EW, Rimm EB, Cannuscio CC, Mandl LA, Manson JE, et al. Cardiovascular morbidity and mortality in women diagnosed with rheumatoid arthritis. Circulation 2003;107:1303-7

18 Wolfe F, Freundlich B, Straus WL. Increase in cardiovascular and cerebrovascular disease prevalence in rheumatoid arthritis. J Rheumatol 2003;30:36-40.

19 Maradit-Kremers H, Crowson CS, Nicola PJ, Ballman KV, Roger VL, Jacobsen SJ, et al. Increased unrecognized coronary heart disease and sudden deaths in rheumatoid arthritis: a population-based cohort study. Arthritis Rheum 2005;52:402-11.

20 Allebeck P. Increased mortality in rheumatoid arthritis. Scand J Rheumatol $1982 ; 11: 81-6$.

21 Erhardt CC, Mumford PA, Venables PJ, Maini RN. Factors predicting a poor life prognosis in rheumatoid arthritis: An eight year prospective study. Ann Rheum Dis 1989;48:7-13.

22 Symmons DP, Jones MA, Scott DL, Prior P. Longterm mortality outcomes in patients with rheumatoid arthritis: Early presenters continue to do well. J Rheumatol 1998;25:1072-7.

23 Chehata JC, Hassell AB, Clarke SA, Mattey DL, Jones MA, Jones PW, et al. Mortality in rheumatoid arthritis: relationship to single and composite measures of disease activity. Rheumatology (Oxford) 2001;40:447-52.

24 Riise T, Jacobsen BK, Gran JT, Haga HJ, Arnesen E. Total mortality is increased in rheumatoid arthritis. A 17-year prospective study. Clin Rheumatol 2001;20:123-7.

25 Greenberg M, Coleman MP. Medical research at the Office for National Statistics: a review (Studies on Medical and Population Subjects). London: HMSO, 2000:65.

26 Department of Health. Hospital episode statistics. http://www.dh.gov.uk/ PublicationsAndStatistics/Statistics/HospitalEpisodeStatistics2005 (accessed March 2005).

27 Kvalvik AG, Jones MA, Symmons DP. Mortality in a cohort of Norwegian patients with rheumatoid arthritis followed from 1977 to 1992 Scand J Rheumatol 2000;29:29-37.

28 Gabriel SE, Crowson CS, Kremers HM, Doran MF, Turesson C, O'Fallon WM, et al. Survival in rheumatoid arthritis - a population-based analysis of trends over 40 years. Arthritis Rheum 2003;48:54-8.

29 Aho K, Heliovaara M. Risk factors for rheumatoid arthritis. Ann Med 2004;36:242-51

30 Arnett FC, Edworthy SM, Bloch DA, McShane DJ, Fries J, Cooper NS. The American Rheumatism Association 1987 revised criteria for the classification of rheumatoid arthritis. Arthritis Rheum 1988;31:315-24.

31 Lindahl BI, Allander E. Problems in the classification of cause of death diagnoses affecting the reliability of mortality statistics for rheumatoid arthritis. J Chronic Dis 1985;38:409-18.

32 Charlton J, Murphy M. Monitoring health-data sources and methods. In: Charlton J, Murphy M, eds. The health of adult Britain: 1841-1994. London: HMSO, 1997:2-16.

33 Williams JG, Mann RY. Hospital episode statistics: time for clinicians to get involved? Clin Med 2002;2:34-7

34 Dixon T, Shaw M, Frankel S, Ebrahim S. Hospital admissions, age, and death: retrospective cohort study. BMJ 2004;328:1288. 
35 Bottle A, Hansell A, Aylin P. Hospital episode statistics: time for clinicians to get involved? Clin Med 2002;2:483-4.

36 Allebeck P, Ahlbom A, Allander E. Increased mortality among persons with rheumatoid arthritis, but where RA does not appear on death certificate.
Eleven-year follow-up of an epidemiological study. Scand J Rheumatol $1981 ; 10: 301-6$.

37 Laakso M, Isomaki $\mathrm{H}$, Mutru O, Koota K. Death certificate and mortality in rheumatoid arthritis. Scand J Rheumatol 1986;15:129-33.

\section{$\mathrm{ECHO}$}

\section{Posture may not prevent pain with computer use}

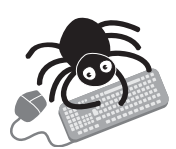

Please visit the Annals of the Rheumatic Diseases website [www. annrheumdis. com] for a link to the full text of this article. osture may not be the key to avoiding aches and pains brought on by using computers, after all, a randomised controlled trial in the Unites States has suggested, so we should be cautious about encouraging any particular posture.

Incidence of musculoskeletal (MS) symptoms in hands or arms and neck or shoulders over six months was no different, nor did the time to noticing symptoms differ significantly, among three groups of newly recruited office workers in the trial. Two groups were randomly assigned to receive postural interventions, and a control group was allowed to carry on as usual. The interventions were based on protective factors derived from a previous prospective study (alternative intervention) or well known national occupational safety and health policies or private company policies (conventional intervention). The main drawback was low compliance-only $25 \%$ for the alternative and $38 \%$ for the conventional intervention-mainly because of inflexible workstations, so a potential effect cannot be ruled out.

The trial included 376 recruits in metropolitan Atlanta, Georgia, using computers for 15 hours or more a week currently and in their previous job. Demographic information, work and medical history, and computer use were collected by questionnaire at enrolment. Computer use was recorded daily by the recruits and symptoms weekly during follow up.

The use of computers has seen an escalation in work related musculoskeletal problems in the upper body. Such a potentially huge impact on public health means it is important that trials test the assumption that posture does protect.

\ Gerr F, et al. Occupational and Environmental Medicine 2005; 62:478-487. 